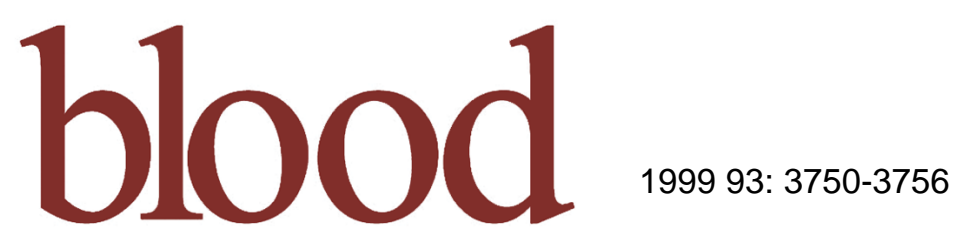

\title{
The Myeloid-Lymphoid Initiating Cell (ML-IC) Assay Assesses the Fate of Multipotent Human Progenitors In Vitro
}

M. Punzel, S.D. Wissink, J.S. Miller, K.A. Moore, I.R. Lemischka and C.M. Verfaillie

Updated information and services can be found at:

http://bloodjournal.hematologylibrary.org/cgi/content/full/93/11/3750

Articles on similar topics may be found in the following Blood collections:

Hematopoiesis and Stem Cells (2715 articles)

Information about reproducing this article in parts or in its entirety may be found online at:

http://bloodjournal.hematologylibrary.org/misc/rights.dtl\#repub_requests

Information about ordering reprints may be found online at:

http://bloodjournal.hematologylibrary.org/misc/rights.dtl\#reprints

Information about subscriptions and ASH membership may be found online at:

http://bloodjournal.hematologylibrary.org/subscriptions/index.dtl

Blood (print ISSN 0006-4971, online ISSN 1528-0020), is published semimonthly by the American Society of Hematology, 1900 M St, NW, Suite 200, Washington DC 20036.

Copyright 2007 by The American Society of Hematology; all rights reserved.

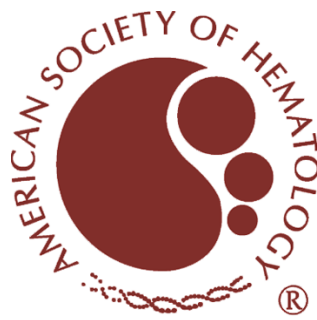




\title{
The Myeloid-Lymphoid Initiating Cell (ML-IC) Assay Assesses the Fate of Multipotent Human Progenitors In Vitro
}

\author{
By M. Punzel, S.D. Wissink, J .S. Miller, K.A. Moore, I.R. Lemischka, and C.M. Verfaillie
}

\begin{abstract}
Hematopoietic stem cells (HSC) are cells with self-renewing multilineage differentiation potential. Although engraftment in xenogeneic recipients can be used to measure human HSC, these assays do not allow assessment of individual progenitors. We developed an in vitro assay that allows the identification of a single human bone marrow progenitor closely related to HSC, which we termed "Myeloid-Lymphoid Initiating Cell," or ML-IC, because it is capable of generating multiple secondary progenitors that can reinitiate long-term myeloid and lymphoid hematopoiesis in vitro. The assay is done in contact with murine AFT024 fetal
\end{abstract}

$\mathbf{H}^{\mathrm{H}}$ EMATOPOIETIC STEM cells (HSC) are defined as cells capable of self renewal as well as multilineage differentiation. In mice, the phenotype and function of HSC have been characterized using competitive in vivo repopulation assays. ${ }^{1-4}$ Because such repopulation assays cannot be performed in humans, surrogate in vivo or in vitro assays are used to evaluate human HSC. Transplantation of human progenitors in xenogeneic transplant recipients, such as severe combined immunodeficient (SCID) mice, ${ }^{5-7}$ beige-nude-SCID (BNX)-mice, ${ }^{8,9}$ nonobese diabetic (NOD)-SCID-mice, ${ }^{10-13}$ or fetal sheep, ${ }^{14,15}$ allows detection of engrafting human cells. In vivo production of myeloid, natural killer (NK), T-lymphoid, and B-lymphoid blood elements is seen for several months to years after transplantation. Through transplantation of limiting numbers of CD $34^{+}$subpopulations, these xenotransplant models provide a quantitative assay for engrafting cells.

A number of in vitro assays have been described that assess primitive human progenitors. These include long-term culture initiating cell (LTC-IC) assays, ${ }^{16}$ cobblestone area forming cell (CAFC) assays, ${ }^{17,18}$ and extended (E)-LTC-IC assays. ${ }^{19}$ These assays enumerate primitive progenitors that can eventually generate myeloid cells, but not cells with multilineage differentiation or self-renewal potential. Several groups have developed

From the Department of Medicine, Division of Hematology and Stem Cell Biology Program, University of Minnesota, Minneapolis, MN; and the Department of Molecular Biology, Princeton University, Princeton, NJ.

Submitted October 19, 1998; accepted January 29, 1999.

Supported in part by National Institutes of Health (NIH) Grants No. RO1-HL-49930, RO1-HL-48738, RO1-HL-58739-01, and PO1-CA-65493. Supported by the University of Minnesota Hospitals and Clinics. M.P. was supported by a Grant from the Deutscher Akademischer Austauschdienst. C.M.V. is a Scholar of the Leukemia Society of America.

Address reprint requests to C.M. Verfaillie, MD, Professor of Medicine, Division of Hematology, Oncology and Transplantation, Director, Stem Cell Biology Program, Box 806 UMHC, 420 Delaware St SE, Minneapolis, MN 55455; e-mail:verfa001@maroon.tc.umn.edu.

The publication costs of this article were defrayed in part by page charge payment. This article must therefore be hereby marked "advertisement" in accordance with 18 U.S.C. section 1734 solely to indicate this fact.

(c) 1999 by The American Society of Hematology.

0006-4971/99/9311-0040\$3.00/0 liver stromal cells and with Flt3-Ligand, stem cell factor, and interleukin-7. In this assay, $0.2 \%$ to $1.7 \%$ of $\mathrm{Lin}^{-} / 34^{+} / \mathrm{DR}^{\mathrm{dim}}$ cells could generate 1 to 3 long-term culture initiating cells (LTC-IC) as well as 1 to 4 NK-IC after 4 to 6 weeks. In addition, this assay measures contribution of net-progenitor conservation and net-progenitor proliferation over time, providing insight in the fate of individual LTC-IC and NK-IC. This assay will prove useful to enumerate the number of very primitive human progenitors with multilineage differentiation potential, as well as to evaluate future ex vivo culture conditions. () 1999 by The American Society of Hematology.

cultures that allow differentiation of single human $\mathrm{CD} 34^{+} \mathrm{Lin}^{-}$ cells into cells with myeloid, NK, B-lymphoid, dendritic, and/or T-lymphoid phenotype showing that a single cell can differentiate in vitro into multiple lineages. ${ }^{20-22}$ Because of its multilineage differentiation capacities, this cell is thought to be more immature than the LTC-IC.

In the work described here, we wanted to develop an assay that would allow us to enumerate even more primitive cells that, besides having multilineage differentiation potential, also can generate secondary primitive progenitors that again have multilineage differentiation potential. A number of observations prompted us to use a stroma-based culture system to accomplish this. Long-term ex vivo maintenance of murine HSC also requires stroma. ${ }^{23}$ It has also been shown that noncommitted human progenitors require stromal cell interactions that cannot be replaced by soluble factors to commit to the B-lymphoid lineage. ${ }^{24-27}$ Our group has recently shown that human $\mathrm{CD}^{2} 4^{+} /$ HLA-DR ${ }^{-} / \mathrm{Lin}^{-}$bone marrow progenitors require stromal contact to differentiate into functional NK cells. ${ }^{28}$

We used the murine fetal liver cell line, AFT024, known to support murine repopulating HSC for up to 7 weeks ex vivo, ${ }^{23}$ as well as human primitive myeloid and lymphoid progenitors. ${ }^{29,30}$ We show that a culture system based on this AFT024 feeder, supplemented with the early acting cytokines Flt3Ligand (Flt3-L), stem cell factor (SCF), and interleukin-7 (IL-7), can enumerate very primitive human progenitors capable of generating multiple secondary progenitors that have the ability of reinitiating long-term multilineage hematopoiesis. We termed these cells Myeloid-Lymphoid Initiating Cells or ML-IC. This single cell assay also provides insight in the mechanisms underlying ex vivo expansion of primitive myeloid and lymphoid progenitors.

\section{MATERIALS AND METHODS}

\section{Cell Source and Preparation}

Bone marrow was aspirated from the posterior iliac crest from healthy volunteer donors after obtaining informed consent using guidelines approved by the Committee on the Use of Human Subjects at the University of Minnesota (Minneapolis, MN). Mononuclear cells (MNC) were obtained by Ficoll-Hypaque (Sigma-Diagnostics, St Louis, MO) centrifugation. $\mathrm{CD} 34^{+}$cells were selected with a biotinylated monoclonal anti-CD34 antibody (clone, 12.8 CePrate system; CellPro Inc, Bothell, WA) on an immunoaffinity column (CellPro). 


\section{Fluorescence-Activated Cell Sorting (FACS)}

$\mathrm{CD}^{+}{ }^{+}$enriched cells were incubated with anti-CD34-Biotin (CellPro), Streptavidin-SA670 (GIBCO-BRL, Grand Island, NY), antiHLA-DR-phycoerythrin (PE) (Becton Dickinson, Mountain View, CA), and a lineage cocktail of fluorescein isothiocyanate (FITC)-conjugated antibodies against CD2, CD3, CD4, CD5, CD7, CD8, CD10, CD14, CD15, CD16, CD19 (Becton-Dickinson). Individual $\mathrm{Lin}^{-} / 34^{+} / \mathrm{DR}^{\mathrm{dim}}$ cells were sorted into 96-well plates (Costar, Cambridge, MA) containing irradiated AFT024 feeders using the automatic cell deposition unit (ACDU) on a FACS Star-Plus flow cytometry system equipped with a Consort 32 computer (Becton Dickinson). To ensure that only a single cell was deposited, the ACDU was set up in a low event "through-put" (200 cells/s). An oscilloscope was used to adjust phasing of the single droplet sort pulse to the drop drive frequency. Accuracy of the single-cell deposition was determined by sorting single cells in 96-well plates without stroma and scoring wells visually for the number of cells deposited: $83 \%$ of the wells contained a single cell, $17 \%$ of the wells did not contain a cell, and no well contained more than one cell.

\section{Stromal Feeder}

The murine fetal liver cell line, AFT024, was maintained at $33^{\circ} \mathrm{C}$ in Dulbecco's modified Eagle's medium (DMEM; GIBCO-BRL) supplemented with $20 \%$ fetal calf serum (FCS; Hyclone Laboratories, Logan, UT), $50 \mu \mathrm{mol} / \mathrm{L}$ 2-Mercaptoethanol (2-ME; Bio-Rad, Hercules, CA). AFT024 cells were subcultured in 24- or 96-well plates (Costar), precoated with $0.1 \%$ gelatin (Specialty Media, Lavalette, NJ), and grown to confluence. Confluent plates were irradiated at 2,000 rad and were maintained at $37^{\circ} \mathrm{C}$.

\section{Culture Media}

Flt3-L/SCF/IL-7 expansion medium. RPMI 1640 (GIBCO-BRL), $20 \% \mathrm{FCS}, 25 \mu \mathrm{mol} / \mathrm{L}$ 2-ME, $1,000 \mathrm{U} / \mathrm{mL}$ penicillin, $100 \mathrm{U} / \mathrm{mL}$ streptomycin (GIBCO-BRL), Flt3-L (10 ng/mL; Amgen, Thousand Oaks, CA), SCF (10 ng/mL; Immunex, Seattle, WA), and IL-7 (20 $\mathrm{ng} / \mathrm{mL} ; \mathrm{R} \& \mathrm{D}$ Systems, Minneapolis, MN).

IL-3/MIP- $1 \alpha$ expansion medium. Iscove's modified Dulbecco's medium (IMDM), $12.5 \%$ FCS, $12.5 \%$ horse serum (Stem Cell Technologies, Vancouver, Canada), $2 \mathrm{mmol} / \mathrm{L}$ L-Glutamine (GIBCO-BRL), $1,000 \mathrm{U} / \mathrm{mL}$ penicillin, $100 \mathrm{U} / \mathrm{mL}$ streptomycin, $10^{-6} \mathrm{~mol} / \mathrm{L}$ hydrocortisone, IL-3 $(5 \mathrm{ng} / \mathrm{mL})$, and macrophage inflammatory protein (MIP)- $1 \alpha$ (100 ng/mL; R\&D Systems).

Lymphoid differentiation medium. DMEM and Ham's F12-medium (GIBCO-BRL) in a 2:1 (vol/vol) mix containing $20 \%$ heat inactivated human $\mathrm{AB}$ serum (North American Biologicals, Miami, FL), ascorbic acid $(20 \mathrm{mg} / \mathrm{mL}$; GIBCO-BRL), selenium selenite $(50 \mu \mathrm{mol}$; GIBCOBRL), 2-ME ( $25 \mu \mathrm{mol})$, and ethanolamine (50 $\mu \mathrm{mol}$; GIBCO-BRL). Cytokines added on day 0: IL-2 (1,000 U/mL; Amgen), IL-3 (5 ng/mL), IL-7 $(20 \mathrm{ng} / \mathrm{mL})$, SCF $(20 \mathrm{ng} / \mathrm{mL})$, and Flt3-L (10 ng/mL). At weekly intervals, half media change was done using $10 \%$ instead of $20 \%$ human
AB serum. Cytokines added at week 1 and later: IL-2 only (1,000 $\mathrm{U} / \mathrm{mL})$.

\section{Single Cell Cultures}

To determine the LTC-IC frequency on day 0, cells were sorted individually in 96-well plates ("day 0 plates"), maintained either in AFT024/Flt3-L/SCF/IL-7 or AFT024/IL-3/MIP- $1 \alpha$ conditions for 5 weeks, and then overlaid with clonogenic methylcellulose medium (Methylcellulose [Fisher, Chicago, IL] in a final concentration of $1.12 \%$ containing IMDM, supplemented with $30 \%$ FCS, 3 IU/mL erythropoietin [Amgen], and supernatant of the bladder carcinoma cell line 5637 [7.5\%]) and scored for secondary colony-forming cell (CFC) after an additional 2 weeks. To determine the NK-culture-initiating cell (IC) frequency on day 0 , single cell cultures were maintained with lymphoid differentiation medium for 5 to 6 weeks. Wells were scored visually for presence of mature progeny. To demonstrate presence of NK cells, wells were harvested and cells were stained with anti-CD56-PE and anti-CD3FITC (Becton Dickinson) and analyzed by FACS to determine the presence of $\mathrm{CD}^{2} 6^{+} \mathrm{NK}$ cells. We also tested secondary CD56 ${ }^{+} \mathrm{NK}$ cells for their capability to kill specifically K562 targets as previously described. ${ }^{31}$

To assess ML-IC, cells were sorted individually in 96-well plates ("expansion cultures") and maintained in either AFT024/Flt3-L/SCF/ II-7 or AFT024/IL-3/MIP-1 $\alpha$ expansion conditions for 4 weeks. The content of a single well was then harvested with trypsin and divided equally over 8 secondary 96-well plates containing irradiated AFT024 feeders in such a manner that one eighth of each single cell progeny was deposited in the identical location in the 8 secondary plates. Four of the 8 secondary plates were maintained in either AFT024/Flt3-L/SCF/IL-7 or AFT024/IL-3/MIP-1 $\alpha$ expansion conditions for an additional 5 weeks and assessed for LTC-IC as described above. The other 4 secondary plates were maintained for 6 to 7 weeks with lymphoid differentiation medium and assessed for the presence of NK cells by FACS. LTC-IC and NK-IC expansion was determined as described in Table 1.

In other experiments, individually sorted $\mathrm{Lin}^{-} / 34^{+} / \mathrm{DR}^{\mathrm{dim}}$ cells were cultured in Flt3-L/SCF/IL-7 expansion medium on AFT024 feeders. After 3 weeks, the primary plates were harvested by trypsinization, and the contents of each well were divided equally into 4 secondary 96-well plates in such a manner that one fourth of the progeny of each single cell was deposited in the identical location in the 4 secondary plates. Secondary cultures were maintained for an additional 3 weeks in Flt3-L/SCF/IL-7 expansion medium. After 6 weeks, secondary plates were harvested by trypsinization, and the contents of each well were divided equally into 4 tertiary 96 -well plates in such a manner that one fourth of the content of each secondary well was deposited in the identical location of the 4 tertiary plates. Two of the tertiary plates ( 8 for each primary plate) were assessed for LTC-IC, and two of the tertiary plates ( 8 for each primary plate) were assessed for NK-IC as described above.

Table 1. LTC-IC Expansion in AFT024/FIt3-L/SCF/ IL-7 Cultures Is Due to LTC-IC Net-Conservation and Net-Proliferation

\begin{tabular}{|c|c|c|c|c|c|c|c|c|}
\hline \multirow[b]{3}{*}{ Exp. } & \multirow{3}{*}{$\begin{array}{c}\text { Day } 0 \\
\text { LTC-IC (\%) }\end{array}$} & \multicolumn{6}{|c|}{ LTC-IC at Week 4} & \multirow[b]{3}{*}{ Fold Expansion } \\
\hline & & \multirow[b]{2}{*}{ Conserved LTC-IC } & \multicolumn{2}{|c|}{ No Proliferation } & \multicolumn{2}{|c|}{ Proliferation } & \multirow[b]{2}{*}{ Total LTC-IC } & \\
\hline & & & 1 LTC-IC & 2 LTC-IC & 3 LTC-IC & 4 LTC-IC & & \\
\hline 1 & $6.9 \%$ & $11 / 132 *(8.3 \%)$ & $4 / 11 \dagger$ & $4 / 11$ & $2 / 11$ & $1 / 11$ & $22 / 132 \ddagger(16.6 \%)$ & 2.4 \\
\hline 2 & $8.5 \%$ & $13 / 132 *(9.8 \%)$ & $8 / 13 \dagger$ & $4 / 13$ & $0 / 13$ & $1 / 13$ & $20 / 132 \ddagger(15.2 \%)$ & 1.8 \\
\hline 3 & $6.8 \%$ & 11/88* (12.5\%) & $5 / 11 \dagger$ & $5 / 11$ & $1 / 11$ & $0 / 11$ & $18 / 88 \ddagger(20.4 \%)$ & 3.0 \\
\hline 4 & $4.2 \%$ & 6/88* (6.8\%) & $4 / 6 \dagger$ & $1 / 6$ & $0 / 6$ & $1 / 6$ & $10 / 88 \ddagger$ (11.4\%) & 2.7 \\
\hline
\end{tabular}

*Number of single-sorted Lin- $/ 34^{+} / \mathrm{DR}^{\mathrm{dim}}$ cells that generated at least 1 secondary LTC-IC per initially plated cell.

†Number of LTC-IC (per conserved LTC-IC) that did not proliferate (only 1 secondary LTC-IC).

$\ddagger$ Total number of secondary LTC-IC per single sorted Lin- $/ 34^{+} / \mathrm{DR}^{\mathrm{dim}}$ cell. 


\section{Definitions}

Overall progenitor expansion is equal to recovery of $>100 \%$ LTC-IC/NK-IC in all week 4 or 6 progeny plates compared with the day 0 plates. Progenitor proliferation is equal to a single cell that gives rise to two or more LTC-IC/NK-IC, ie, can reinitiate hematopoiesis in at least 2 secondary plates. Progenitor conservation is equal to a single cell that persists over time with or without proliferation, ie, can reinitiate hematopoiesis in at least one secondary LTC-IC/NK-IC culture. Progenitor recruitment is equal to a single cell that reads out as an LTC-IC/ NK-IC after 4 to 6 weeks, but not on day 0 .

\section{Statistics}

Results of experimental points from different experiments were reported as the mean \pm standard error of the mean (SEM). Significance levels were determined by either paired or nonpaired two-sided Student's $t$-test analysis as indicated.

\section{RESULTS}

Measurement of Multilineage Initiating Cells

To determine if a single cell can give rise to secondary progenitors with both LTC-IC and NK-IC characteristics, we cultured single $\mathrm{Lin}^{-} / 34^{+} / \mathrm{DR}^{\mathrm{dim}}$ cells from 4 individual donors (176 to 264 cells per donor) in Flt3-L/SCF/IL-7 expansion medium on AFT024 feeders. After 4 weeks, one eighth of the contents of each individual well was replated in the identical location of 8 secondary AFT024-containing 96-well plates. Four of the 8 secondary plates were maintained for 5 weeks in Flt3-L/SCF/IL-7 expansion medium and then overlaid with clonogenic methylcellulose medium to assess presence of LTC-IC in single-cell progeny. To assess NK-IC, the other 4 plates were maintained under lymphoid differentiation condi-

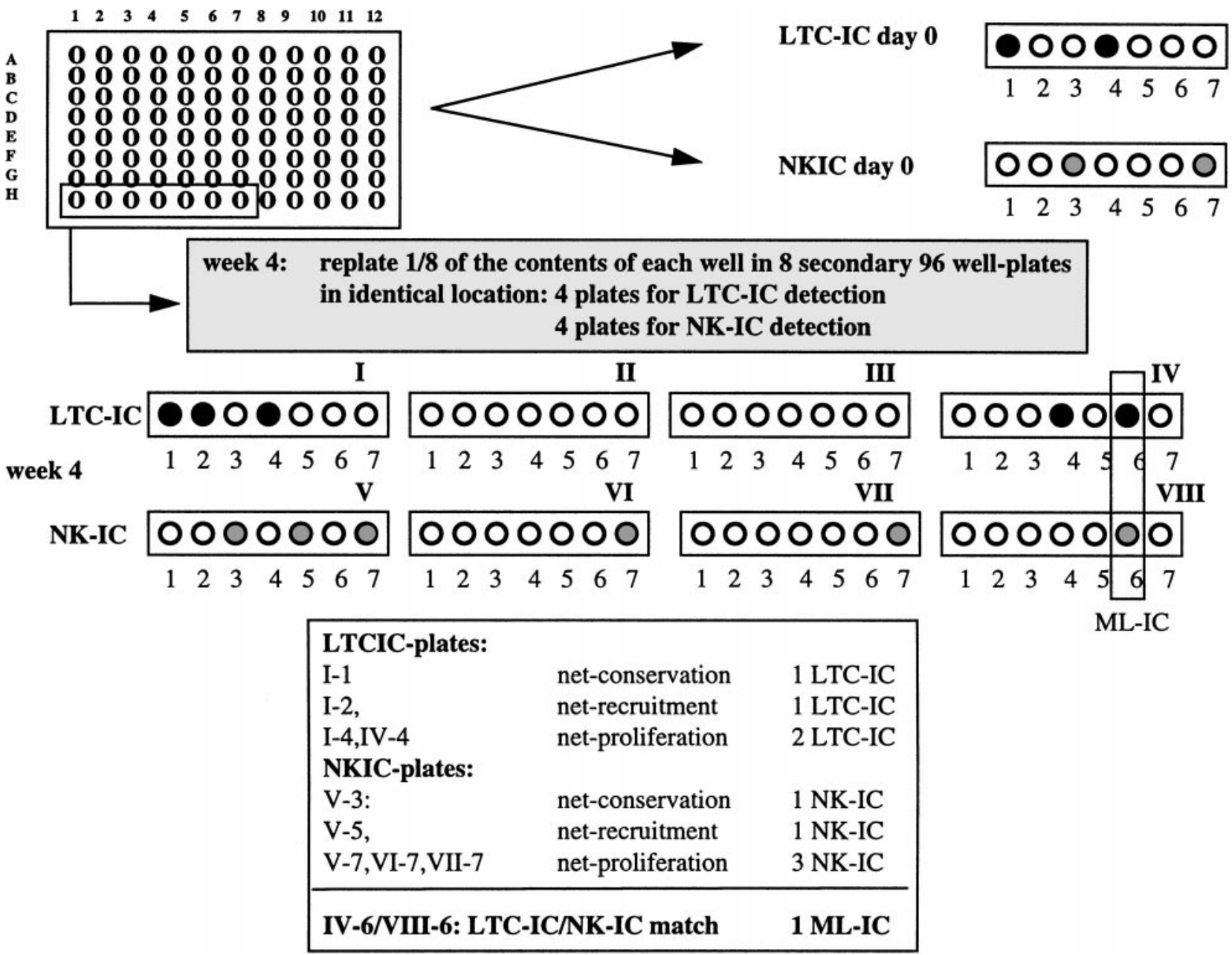

Fig 1. Single cell cultures. Lin-/34+/ RRim $^{\text {dim }}$ cells were sorted into 88 wells of 96-well plates with AFT024 stromal feeders using the FACS Star Plus ACDU system. Cells were cultured as indicated with weekly medium exchange. After 4 weeks, the content of each well was collected by trypsinization and divided equally over 8 secondary 96-well plates with pre-established AFT024 feeders in such a manner that one eighth of the content was deposited in the identical location in the 8 secondary plates, 4 for LTC-IC detection and 4 for NK-IC detection. To detect LTC-IC/ NK-IC at day 0, single cells were cultured in 96-well plates containing AFT024 feeders for 5 weeks, and plates were overlaid with clonogenic methylcellulose. To detect NK-IC at day 0, single cells were cultured in separate 96-well plates containing AFT024 feeders as described in Materials and Methods. An ML-IC is defined as a single Lin- $/ \mathbf{3 4}^{+} / \mathrm{DR}^{\mathrm{dim}}$ cell with multilineage generative capacity, ie, this cell can generate at least one LTC-IC and one NK-IC. 


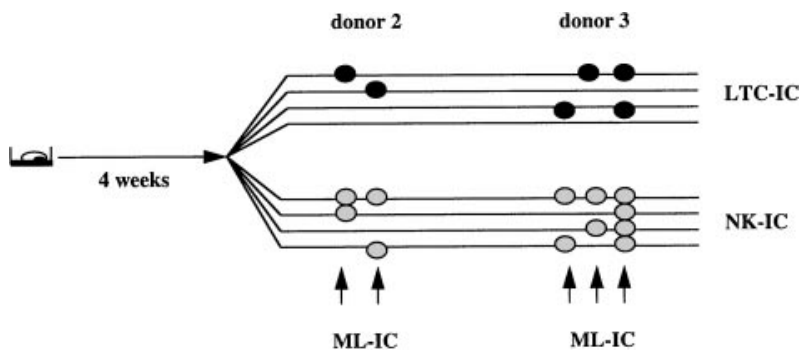

Fig 2. $0.8 \%$ to $1.7 \%$ of $\mathrm{Lin}^{-} / 34^{+} / \mathrm{DR}^{\mathrm{dim}}$ cells are myeloid-lymphoid initiating cells. Progeny from single $\mathrm{Lin}^{-} / \mathrm{34}^{+} / \mathrm{DR}^{\mathrm{dim}}$ cells cultured on AFT024 in expansion medium with FIt3-L, SCF, and IL-7 were replated after 4 weeks in 8 secondary plates. Four secondary plates were maintained in expansion medium with Flt3-L, SCF, and IL-7 to enumerate LTC-IC. The remaining 4 secondary plates were maintained in lymphoid differentiation medium to detect NK-IC. Lin- $/ 34^{+} /$ DR dim cells that generated $\geq 1$ LTC-IC (black circles) and $\geq 1$ NK-IC (gray circles) were identified as ML-IC.

tions for 6 to 7 weeks (Fig 1). Detection of $\geq 1$ LTC-IC and $\geq 1$ NK-IC in the identical location in secondary plates was required to consider the initially plated $\mathrm{Lin}^{-} / 34^{+} / \mathrm{DR}^{\mathrm{dim}}$ cell an ML-IC.

In 2 out of 4 donors, we found that $0.8 \%$ and $1.7 \%$ of $\mathrm{Lin}^{-} / 34^{+} / \mathrm{DR}^{\mathrm{dim}}$ cells could generate both secondary LTC-IC and NK-IC after the initial 4-week expansion culture, or were ML-IC. Each initially sorted ML-IC gave rise to 1 or 2 LTC-IC, as well as 2 to 4 NK-IC. In the other 2 donors, such cells were not detected (Fig 2). In additional experiments, we extended the initial culture in Flt3-L/SCF/IL-7 expansion medium to 6 weeks (data not shown). We detected ML-IC in 3 of 4 donors. The frequency of ML-IC ranged between $0.2 \%$ and $0.7 \%$, and each ML-IC generated 1 to 3 LTC-IC and 1 NK-IC.

\section{Net-Conservation and Net-Proliferation Contribute to LTC-IC and NK-IC Expansion in Flt3-L/SCF/IL-7 Expansion Medium Cultures}

We hypothesized that this single cell assay with LTC-IC and NK-IC readout assays would also provide information on the fate of a single LTC-IC or NK-IC progenitor over time; specifically, if an LTC-IC or NK-IC persists over time or if there is net conservation, and if a single cell can give rise to two or more LTC-IC or NK-IC (net-proliferation) during the primary culture step.

Single $\mathrm{Lin}^{-} / 34^{+} / \mathrm{DR}^{\mathrm{dim}}$ cells were cultured in Flt3-L/SCF/ IL-7 expansion medium for 4 weeks, and progeny were evaluated for LTC-IC and NK-IC, as described above. The absolute number of $\mathrm{Lin}^{-} / 34^{+} / \mathrm{DR}^{\mathrm{dim}}$ cells capable of initiating long-term cultures on day 0 was $6.6 \% \pm 0.9 \%$. Of the initially plated $\mathrm{Lin}^{-} / 34^{+} / \mathrm{DR}^{\mathrm{dim}}$ cells, $9.3 \% \pm 1.2 \%$ were capable of initiating and sustaining hematopoiesis in one or more secondary stromal cultures. Thus, culture for 4 weeks in Flt3-L/SCF/ IL-7 expansion medium on AFT024 feeders supported net conservation of LTC-IC. Cultured progeny of $47.5 \% \pm 7 \%$ of single $\mathrm{Lin}^{-} / 34^{+} / \mathrm{DR}^{\mathrm{dim}} \mathrm{LTC}$-IC were able to initiate hematopoiesis in 2, 3, or 4 secondary long-term cultures and had therefore proliferated. The overall LTC-IC frequency after 4 weeks, or all LTC-IC present in the 4 secondary cultures, was $15.9 \% \pm 1.8 \%$, or $2.5 \pm 0.2-$ fold higher than that measured in day $0 \mathrm{Lin}^{-} / 34^{+} /$ $\mathrm{DR}^{\mathrm{dim}}$ cells (Table 1). In three additional experiments, all 8 secondary plates were evaluated for the presence of secondary LTC-IC. The maximal number of secondary LTC-IC generated from one individual cell was 6 .

To examine the fate of single NK-IC, progeny of the primary Flt3-L/SCF/IL-7 expansion medium cultures were replated in contact with AFT024 feeders with lymphoid differentiation medium for 6 to 7 weeks. The NK-IC frequency in freshly sorted $\mathrm{Lin}^{-} / 34^{+} / \mathrm{DR}^{\mathrm{dim}}$ cells measured by culturing for 6 to 7 weeks in lymphoid differentiation medium was $0.12 \% \pm$ $0.02 \%$. In 3 of 4 experiments, progeny of $3.9 \% \pm 1.7 \%$ of the initial $\mathrm{Lin}^{-} / 34^{+} / \mathrm{DR}^{\mathrm{dim}}$ cells cultured for 4 weeks in expansion medium were capable of generating functional NK cells in one or more secondary lymphoid differentiation cultures indicating net conservation of NK-IC (Table 2). $46 \% \pm 26 \%$ of singlesorted $\mathrm{Lin}^{-} / 34^{+} / \mathrm{DR}^{\mathrm{dim}}$ cells that generated NK-IC after 4 weeks could initiate 2 to 4 secondary NK long-term cultures, indicating proliferation. Thus, a total of 33 NK-IC $(7.5 \% \pm 3.7 \%)$ was present in all 4 secondary cultures initiated with progeny of $440 \mathrm{Lin}^{-} / 34^{+} / \mathrm{DR}^{\mathrm{dim}}$ cells, which is $37.3 \pm$ 19-fold higher than the day 0 frequency of NK-IC.

Lack of Progenitor Proliferation Is Responsible for Lack of LTC-IC and NK-IC Expansion in IL-3/MIP-1 $\alpha$ Expansion Medium Cultures

To confirm that this assay will be helpful in assessing the contribution of net proliferation and net conservation of progenitors to overall progenitor expansion, we cultured single-sorted $\mathrm{Lin}^{-} / 34^{+} / \mathrm{DR}^{\mathrm{dim}}$ cells from 5 donors in contact with AFT024 feeders under conditions known to maintain LTC-IC, namely IL-3/MIP-1 $\alpha$ expansion medium (unpublished observations). We hypothesized that our assay should show that lack of expansion is caused by either poor conservation or poor

Table 2. NK-IC Expansion in AFT024/ FIt3-L/SCF/IL-7 Cultures Is Due to NK-IC Net-Conservation and Net-Proliferation

\begin{tabular}{|c|c|c|c|c|c|c|c|c|}
\hline \multirow[b]{3}{*}{ Exp. } & \multirow{3}{*}{$\begin{array}{c}\text { Day } 0 \\
\text { NK-IC (\%) }\end{array}$} & \multicolumn{6}{|c|}{ NK-IC at Week 4} & \multirow[b]{3}{*}{ Fold Expansion } \\
\hline & & \multirow[b]{2}{*}{ Conserved NK-IC } & \multirow{2}{*}{$\frac{\begin{array}{c}\text { No } \\
\text { Proliferation }\end{array}}{1 \mathrm{NK}-\mathrm{IC}}$} & \multicolumn{3}{|c|}{ Proliferation } & \multirow[b]{2}{*}{ Total NK-IC } & \\
\hline & & & & 2 NK-IC & 3 NK-IC & 4 NK-IC & & \\
\hline 1 & $<0.2 \%$ & $3 / 132 *(2.3 \%)$ & $3 / 3+$ & $0 / 3$ & $0 / 3$ & $0 / 3$ & $3 / 132 \ddagger(2.2 \%)$ & $>11$ \\
\hline 2 & $<0.2 \%$ & 9/132* (6.8\%) & 2/9† & $6 / 9$ & $1 / 9$ & $0 / 9$ & $17 / 132 \ddagger(12.9 \%)$ & $>64$ \\
\hline 3 & $<0.2 \%$ & 6/88* (6.8\%) & $1 / 6 \dagger$ & $4 / 6$ & $0 / 6$ & $1 / 6$ & 13/88ł (14.8\%) & $>74$ \\
\hline 4 & $<0.2 \%$ & $0 / 88 *(<1.1 \%)$ & 0 & 0 & 0 & 0 & $0 / 88 \ddagger(<1.1 \%)$ & NE \\
\hline
\end{tabular}

Abbreviation: NE, not evaluated.

*Number of single-sorted Lin ${ }^{-} / 34^{+} / \mathrm{DR}^{\mathrm{dim}}$ cells that generated at least 1 secondary NK-IC per initially plated cell.

†Number of NK-IC (per conserved/recruited NK-IC) that did not proliferate (only 1 secondary NK-IC).

¥Total number of secondary NK-IC per single sorted Lin- ${ }^{-} 34^{+} / \mathrm{DR}^{\mathrm{dim}}$ cell. 
proliferation of LTC-IC and NK-IC. After culture of single $\mathrm{Lin}^{-} / 34^{+} / \mathrm{DR}^{\mathrm{dim}}$ cells for 4 weeks in IL-3/MIP-1 $\alpha$ expansion medium, the contents of each well of the primary cultures were replated in 8 secondary AFT024-containing 96-well plates to assess presence of LTC-IC (4 plates) and NK-IC (4 plates). On day $0,7.7 \% \pm 1.5 \%$ of $\mathrm{Lin}^{-} / 34^{+} / \mathrm{DR}^{\mathrm{dim}}$ cells had LTC-IC characteristics. After 4 weeks in IL-3/MIP- $1 \alpha$ expansion medium, $6.5 \% \pm 1.2 \%$ of the initially plated $\mathrm{Lin}^{-} / 34^{+} / \mathrm{DR}^{\mathrm{dim}}$ cells could initiate hematopoiesis in one or more secondary cultures, indicating net conservation of LTC-IC. In contrast to the Flt3-L/SCF/IL-7 expansion medium cultures, only $13.9 \% \pm$ $8.5 \%$ of the single $\mathrm{Lin}^{-} / 34^{+} / \mathrm{DR}^{\mathrm{dim}}$ gave rise to more than 1 LTC-IC. The overall LTC-IC frequency of $8.6 \% \pm 2.1 \%$ at week 4 was only 1.2 -fold higher than that measured in freshly sorted $\mathrm{Lin}^{-} / 34^{+} / \mathrm{DR}^{\mathrm{dim}}$ cells (Table 3 ). Thus, lack of long-term expansion is caused by poor proliferation, and not poor net-conservation. Further, only 4 of $528 \mathrm{Lin}^{-} / 34^{+} / \mathrm{DR}^{\mathrm{dim}}$ cells cultured for 4 weeks in IL-3/MIP- $1 \alpha$ expansion medium cultures could generate one or more NK-IC in secondary cultures. Finally, no ML-IC could be detected under these conditions.

\section{DISCUSSION}

In this report, we describe a novel in vitro assay that can enumerate very primitive human progenitors capable of generating multiple secondary LTC-IC and NK-IC. We term this primitive progenitor a Myeloid-Lymphoid Initiating Cell, or

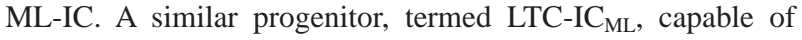
initiating secondary long-term myeloid cultures as well as pre-B cell cultures, has been characterized in murine bone marrow. ${ }^{32}$ As for the human ML-IC, which is five to ten times less frequent than human LTC-IC, murine $\mathrm{LTC}_{\mathrm{IC}} \mathrm{ML}$ are 15 times less frequent than murine LTC-IC. A number of studies have described assays that allow human progenitors to differentiate into mature myeloid as well as NK and B- and T-lymphoid cells. ${ }^{20-22,33-36}$ The assay described here can assess a possibly even more primitive human bone marrow cell capable of generating multiple secondary progenitors that can reinitiate both myeloid and lymphoid long-term cultures. We believe that this characteristic places the ML-IC ontogenetically very close to the HSC. We have, however, not proven that ML-IC can self-replicate. Therefore, we have not yet shown that ML-IC are human HSC. This will require retroviral tagging. The frequency of ML-ICs is still 10-fold higher than that of SCID-repopulating cells (SRCs), as defined by Larochelle et al. ${ }^{10}$ Thus, ML-IC may still contain a population of cells that is less primitive than SRC.
Alternatively, differences in frequency may be related to the relative inefficient seeding efficiency of human cells in vivo, leading to underestimation of the absolute number of engrafting human cells. Studies are currently underway to address the relation between SRC and ML-IC.

What are the disadvantages and advantages of the ML-IC assay over the SRC assay? A disadvantage of the ML-IC assay is the cumbersome nature of the technically demanding longterm culture system. A second disadvantage of the ML-IC assay is that "engraftment" per se-a characteristic ascribed to stem cells-cannot be shown. The first advantage of the ML-IC assay is that it can provide information concerning the multipotentiality of a single-sorted CD34 cell. Similar information can be obtained from experiments in which retrovirally tagged human progenitors are transplanted in immunodeficient mice.

Another advantage of the ML-IC assay is that it provides insight into the fate of single LTC-IC and NK-IC cells in ex vivo cultures. We show, for instance, that differences in LTC-IC or NK-IC expansion in different culture systems can be attributed to variable losses in progenitor conservation or progenitor proliferation. These conclusions are in part indirect because progenitor differentiation can occur in the presence or absence of progenitor proliferation. Indeed, an LTC-IC can remain quiescent for the duration of the expansion culture and retain its LTC-IC function. Alternatively, an LTC-IC can die or remain quiescent, but differentiate. Finally, an LTC-IC can proliferate symmetrically or asymmetrically. Each of these outcomes can be investigated using the ML-IC assay.

In Fig 3 we included data previously described by our group, ${ }^{37}$ using stroma-conditioned medium supplemented with IL-3 + MIP-1 $\alpha$ (SCM/IL-3/MIP-1 $\alpha)$. By comparing the expansion systems, we show that presence of AFT024 feeders in the culture is important for net conservation of LTC-IC (and NK-IC). Net conservation of $80 \%$ to $130 \%$ of LTC-IC and $>100 \%$ of NK-IC is observed in AFT024-based cultures, and this irrespective of the expansion medium, whereas $<30 \%$ of LTC-IC is conserved in SCM + IL-3 + MIP-1 $\alpha$ (Fig 3). Thus, factor(s) produced by AFT024 may be responsible for the net conservation of LTC-IC. Moore et al have shown that AFT024 feeders support the in vitro maintenance of competitive repopulating murine stem cells for at least 7 weeks. ${ }^{23}$ It is thought that expression of one or more novel factors in AFT024 cells is responsible for the improved maintenance of repopulating murine stem cells and possibly for the improved conservation of LTC-IC. One such factor may be the delta-like (dlk) protein/ preadipocyte factor-1 (pref-1), which is produced by AFT024

Table 3. LTC-IC Expansion in AFT024/MIP-1 $\alpha$ / IL-3 Cultures Is Due to LTC-IC Net-Conservation but Only Limited Net-Proliferation

\begin{tabular}{|c|c|c|c|c|c|c|c|c|}
\hline \multirow[b]{3}{*}{ Exp. } & \multirow{3}{*}{$\begin{array}{c}\text { Day } 0 \\
\text { LTC-IC (\%) }\end{array}$} & \multicolumn{6}{|c|}{ LTC-IC at Week 4} & \multirow[b]{3}{*}{ Fold Expansion } \\
\hline & & \multirow[b]{2}{*}{ Conserved LTC-IC } & \multicolumn{2}{|c|}{ No Proliferation } & \multicolumn{2}{|c|}{ Proliferation } & \multirow[b]{2}{*}{ Total LTC-IC } & \\
\hline & & & 1 LTC-IC & 2 LTC-IC & 3 LTC-IC & 4-6 LTC-IC & & \\
\hline 1 & $8.1 \%$ & 11/132* (8.3\%) & $7 / 11 \dagger$ & $2 / 11$ & $2 / 11$ & 0/11 & $17 / 132 \ddagger(12.9 \%)$ & 1.6 \\
\hline 2 & $5.9 \%$ & 8/132* (6.1\%) & $8 / 8+$ & $0 / 8$ & $0 / 8$ & $0 / 8$ & $8 / 132 \ddagger(6.1 \%)$ & 1.0 \\
\hline 3 & $8.0 \%$ & $15 / 180 *(8.3 \%)$ & $10 / 15 \dagger$ & $2 / 15$ & $2 / 15$ & $1 \S / 15$ & $25 / 180 \ddagger(13.9 \%)$ & 1.7 \\
\hline 4 & $4.0 \%$ & 4/187* (2.1\%) & $4 / 4 \dagger$ & $0 / 4$ & $0 / 4$ & $0 / 4$ & $4 / 187 \ddagger(2.1 \%)$ & 0.5 \\
\hline 5 & $12.9 \%$ & 14/176* (7.9\%) & $14 / 14 \dagger$ & $0 / 14$ & $0 / 14$ & $0 / 14$ & 14/176* (7.9\%) & 0.6 \\
\hline
\end{tabular}

*Number of single-sorted $\mathrm{Lin}^{-} / 34^{+} / \mathrm{DR}^{\mathrm{dim}}$ cells that generated at least 1 secondary LTC-IC per initially plated cell.

†Number of LTC-IC (per conserved LTC-IC) that did not proliferate (only 1 secondary LTC-IC).

$\ddagger$ Total number of secondary LTC-IC per single sorted Lin- $/ 34^{+} / \mathrm{DR}^{\mathrm{dim}}$ cell.

§Progeny from initially plated single cells was divided into 6 secondary plates. This particular progenitor generated 5 secondary LTC-IC. 

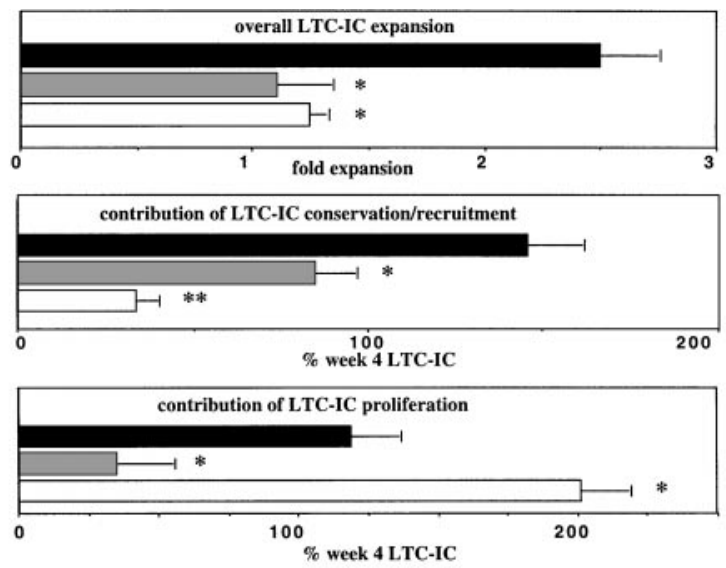

AFT024 [FIt-3L/SCF/IL-7] $\square$ AFT024 [IL-3/MIP-1a] $\square$ SCM [IL-3/MIP-1a]

Fig 3. Contribution of proliferation and conservation to overall LTC-IC expansion. Single cell assays were performed as described in Methods and Fig 2 legend. In addition, we used data from a study previously published by our group in which LTC-IC were assessed in a single cell assay based on bone marrow (BM) stroma-conditioned media supplemented with IL-3 and MIP-1 $\alpha$ in the absence of a stromal feeder. ${ }^{37}$ Significantly greater LTC-IC expansion is seen in AFT024/ Flt3L/SCF/IL-7 cultures than in AFT024/IL-3/MIP-1 $\alpha$ cultures or SCM/ AFT024/IL-3/MIP-1 $\alpha$ cultures. This is a result of both increased proliferation and consenvation when compared with AFT024/ IL-3/ MIP-1 $\alpha$ cultures. The equivalent LTC-IC expansion seen in AFT024/IL3/MIP-1 $\alpha$ and SCM/IL-3/ MIP-1 $\alpha$ cultures is caused by different mechanisms: extensive self-renewal $(80.5 \% \pm 7.0 \%)$ of only $33.9 \% \pm 6.0 \%$ conserved LTC-IC in SCM/IL-3/MIP-1 $\alpha$ cultures and minimal selfrenewal $(13.9 \% \pm 8.6 \%)$ of $84.8 \% \pm 11.5 \%$ conserved LTC-IC in AFT024/ IL-3/MIP-1 $\alpha$ cultures. $* \boldsymbol{P}<0.05$; $* * \boldsymbol{P}<0.01$.

cells, but not by nonsupportive feeders. ${ }^{38}$ When dlk/pref- 1 is introduced in nonsupportive feeders, ex vivo maintenance of murine repopulating stem cells can in part be restored. ${ }^{38}$ Dlk/pref-1 is related to the family of Notch ligands. ${ }^{39-41}$ Expression of dlk/pref-1 is downregulated in embryonic tissues during differentiation, and its overexpression prevents terminal differentiation, similar to what is seen with Notch-ligand/Notchreceptor interactions. ${ }^{39-41}$ However, dlk/pref-1 does not contain the delta/serrate/lag-2 (DSL)-domain, thought to be required for the binding of Notch ligands to their receptors. ${ }^{40}$ Alternatively, AFT024 feeders may produce other novel factors responsible for the improved conservation of primitive progenitors. ${ }^{42,43}$

These same studies also show that more than $80 \%$ of LTC-IC proliferated in SCM/IL-3/MIP-1 $\alpha$ cultures, but less than $20 \%$ in AFT024/IL-3/MIP-1 $\alpha$ cultures (Fig 3). This could be a result of contact-mediated proliferation inhibition of progenitors cultured in contact with AFT024 cells because we have previously shown that contact between progenitors and stromal components, such as fibronectin, inhibits proliferation. ${ }^{44,45}$ We cannot exclude that some factors present in human marrow-conditioned medium, but not in long-term bone marrow culture (LTBMC) medium used in AFT024/IL-3/MIP-1 $\alpha$, may contribute to the increased proliferation in SCM/IL-3/MIP- $1 \alpha$ conditions. Of interest, approximately $50 \%$ of the conserved LTC-IC and NK-IC proliferated in AFT024/Flt3-L/SCF/IL-7, the only culture condition allowing significant expansion of LTC-IC and NK-IC. Thus, conservation as well as proliferation is necessary for an effective expansion of primitive progenitors.

In comparing the different culture conditions (AFT024/Flt3-
L/SCF/IL-7 and AFT024/IL-3/MIP-1 $\alpha$ ), we used different culture conditions in the readout system to assess the number of LTC-IC that was present. One could argue that differences in the perceived LTC-IC proliferation and conservation are secondary to the differences in the readout phase, but not the expansion culture phase of the assay. We have, however, previously shown that that assessment of LTC-IC maintenance is similar when measured on AFT024 feeders with or without IL-3/MIP- $1 \alpha{ }^{30}$ We show here that the number of LTC-IC measured in single cell assays on AFT024 feeders is equivalent when done in Flt3-L/SCF/IL-7 medium (6.6\% $\pm 0.9 \%$ LTC-IC frequency) or in IL-3/MIP- $1 \alpha$ medium $(7.8 \% \pm 1.5 \%$ LTC-IC frequency). Therefore, we believe that differences seen between AFT024/ Flt3-L/SCF/IL-7 and AFT024/IL-3/MIP- $1 \alpha$ expansion cultures are not a result of differences in our ability to assess LTC-IC in the readout phase of the assay.

In conclusion, we developed an assay that provides indirect insight in the fate of single primitive LTC-IC and NK-IC. Although the information on progenitor proliferation and conservation is in part indirect, insight in the role of net-conservation and net-proliferation of progenitors in a given culture system can be used to guide the investigator in the design of improved expansion systems that are adjusted to increase progenitor conservation and/or proliferation. In addition, this assay allows enumeration of a very primitive progenitor capable of generating multiple secondary LTC-IC and NK-IC, which we termed an ML-IC. This cell is ontogenetically closely related to the HSC. The ML-IC assay can show that a single cell can generate multiple progenitors with multilineage potential. Studies are ongoing to determine what the relationship is between ML-IC and SRC.

\section{ACKNOWLEDGMENT}

The authors thank Brad Anderson, Kelly Asleson, Valery McCullar, and Kirk VanOverbeke for their excellent technical help.

\section{REFERENCES}

1. Hodgson GS, Bradley TR: Properties of hematopoietic stem cells surviving 5-fluorouracil treatment. Nature 281:381, 1979

2. Spangrude GJ, Heimfeld S, Weissman IL: Purification and characterization of mouse hematopoietic stem cells. Science 241:58, 1988

3. Spangrude GJ, Johnson JR: Resting and activated subsets of mouse multipotent hematopoietic stem cells. Proc Natl Acad Sci USA 87:7433, 1990

4. Morrison SJ, Weissman IL: The long-term repopulating subset of hematopoietic stem cells is deterministic and isolatable by phenotype. Immunity 1:661, 1994

5. McCune JM, Namikawa R, Kaneshima H, Schultz LD, Lieberman M, Weissman IL: The SCID-hu mouse: Murine model for the analysis of human hematolymphoid differentiation and function. Science 24: 1632,1988

6. Fraser CC, Kaneshima H, Hansteen G, Kilpatrick M, Hoffman R, Chen BP: Human allogeneic stem cell maintenance and differentiation in a long-term multilineage SCID-hu graft. Blood 86:1680, 1995

7. Kollmann TR, Kim A, Zhuang X, Hachamovitch M, Goldstein H: Reconstitution of SCID mice with human lymphoid and myeloid cells after transplantation with human fetal bone marrow without the requirement for exogenous human cytokines. Proc Natl Acad Sci USA 91:8032, 1994

8. Nolta JA, Smogorzewska EM, Kohn DB: Analysis of optimal conditions for retroviral mediated transduction of primitive human hematopoietic cells. Blood 86:101, 1995 
9. Nolta JA, Dao MA, Wells S, Smogorzewska EM, Kohn DB: Transduction of pluripotent human hematopoietic stem cells demonstrated by clonal analysis after engraftment in immune-deficient mice. Proc Natl Acad Sci USA 93:2414, 1996

10. Larochelle A, Vormoor J, Hanenberg H, Wang JC, Bhatia M, Lapidot T, Moritz T, Murdoch B, Xiao XL, Kato I, Williams DA, Dick JE: Identification of primitive human hematopoietic cells capable of repopulating NOD/SCID mouse bone marrow: Implications for gene therapy. Nat Med 2:1329, 1996

11. Gan OI, Murdoch B, Larochelle A, Dick JE: Differential maintenance of primitive human SCID-repopulating cells, clonogenic progenitors, and long-term culture-initiating cells after incubation on human bone marrow stromal cells. Blood 90:641, 1997

12. Bhatia M, Wang JCY, Knapp U, Bonnet D, Dick JE: Purification of primitive human hematopoietic cells capable of repopulating immunedeficient mice. Proc Natl Acad Sci USA 94:5320, 1997

13. Cashman J, Bockhold K, Hogge DE, Eaves AC, Eaves CJ: Sustained proliferation, multi-lineage differentiation and maintenance of primitive human hematopoietic cells in NOD/SCID mice transplanted with human cord blood. Br J Haematol 98:1026, 1997

14. Srour EF, Zanjani ED, Cornetta K, Traycoff CM, Flake AW, Hedrick M, Brandt JE, Leemhuis T, Hoffman R: Persistence of human multilineage, self-renewing lymphohematopoietic stem cells in chimeric sheep. Blood 82:3333, 1993

15. Zanjani ED, Almeida-Porada G, Ascensao JL, MacKintosh FR, Flake AW: Transplantation of hematopoietic stem cells in utero. Stem Cells 15:79, 1997 (suppl 1)

16. Sutherland HJ, Lansdorp PM, Henkelman DH, Eaves AC, Eaves CJ: Functional characterization of individual hematopoietic stem cells cultured at limiting dilution on supportive marrow stroma layers. Proc Natl Acad Sci USA 87:3584, 1990

17. Ploemacher RE, van der Sluijs JP, Voerman JS, Brons NH: An in vitro limiting dilution assay of long-term repopulating hematopoietic stem cells in the mouse. Blood 74:2755, 1989

18. Breems DA, Blokland EAW, Neben S, Ploemacher RE: Frequency analysis of human primitive haematopoietic stem cell subsets using a cobblestone area forming cell assay. Leukemia 8:1095, 1994

19. Hao QL, Thiemann FT, Petersen D, Smogorzewska EM, Crooks GM: Extended long term culture reveals a highly quiescent and primitive human hematopoietic progenitor population. Blood 88:3306, 1996

20. Hao QL, Smogorzewska EM, Barsky LW, Crooks GM: In vitro identification of single CD34+/CD38- cells with both lymphoid and myeloid potential. Blood 91:4145, 1998

21. Miller JS, McCullar V, Punzel M, Lemischka IR, Moore KA: Single adult human $\mathrm{CD} 34^{+} / \mathrm{Lin}^{-} / \mathrm{CD} 38^{-}$progenitors give rise to $\mathrm{NK}$ cells, B-lineage cells, dendritic cells and myeloid cells. Blood 93:96, 1999

22. Baum CM, Weissman IL, Tsukamoto AS, Buckle AM, Peault B: Isolation of a candidate human hematopoietic stem cell population. Proc Natl Acad Sci USA 89:2804, 1992

23. Moore KA, Hideo E, Lemischka IR: In vitro maintenance of highly purified, transplantable hematopoietic stem cells. Blood 89: 4337, 1997

24. Whitlock C, Witte O: Long-term culture of B-lymphocytes and their precursors from murine bone marrow. Proc Natl Acad Sci USA 79:3608, 1982

25. Kierney PC, Dorschkind K: B lymphocyte precursors and myeloid precursors survive in diffusion chamber cultures but B cell differentiation requires close association with stromal cells. Blood 70:1418, 1987

26. Neuberger MS: Antigen receptor signaling gives lymphocytes a long life. Cell 90:971, 1997

27. LeBien TW: B-cell lymphopoiesis in mouse and man. Curr Opin Immunol 10:188, 1998
28. Miller JS, Alley KA, McGlave PB: Differentiation of human natural killer (NK) cells from human primitive marrow progenitors in a stroma-based long-term culture system: Identification of a CD34 $4^{+} 7^{+}$ NK progenitor. Blood 83:2594, 1994

29. Punzel M, Miller JS, Verfaillie CM: The mouse fetal liver cell line, AFT024, supports human myelopoiesis and lymphopoiesis better than primary stroma, but this requires contact with the feeder. Blood 88:2128a, 1996 (abstr)

30. Punzel M, Moore KA, Lemischka IR, Verfaillie CM: The type of stromal feeder used in limiting dilution assays influences frequency and maintenance assessment of human long-term culture initiating cells. Leukemia (in press)

31. Miller JS, Oelkers S, Verfaillie CM, McGlave PB: Role of monocytes in the expansion of human activated natural killer cells. Blood 80:2221, 1992

32. Lemieux ME, Eaves CJ: Identification of properties that can distinguish primitive populations of stromal cell-responsive lymphomyeloid cells from cells that are stromal cell-responsive but lymphoidrestricted and cells that have lympho-myeloid potential but are also capable of competitively repopulating myeloablated recipients. Blood $88: 1639,1996$

33. Huang S, Terstappen LWM: Lymphoid and myeloid differentia-

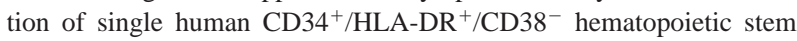
cells. Blood 83:1515, 1994

34. Borge OJ, Ramsfjell V, Cui L, Jacobsen SEW: Ability of early acting cytokines to directly promote survival and suppress apoptosis of human primitive $\mathrm{CD} 34^{+} \mathrm{CD} 38^{-}$bone marrow cells with multilineage potential at the single-cell level: Key role of thrombopoietin. Blood 90:2282, 1997

35. Berardi AC, Meffre E, Pflumio F, Katz A, Vainchenker W, Schiff $\mathrm{C}$, Coulombel L: Individual $\mathrm{CD} 34^{+} \mathrm{CD} 38^{\text {low }} \mathrm{CD} 19^{-} \mathrm{CD} 10^{-}$progenitor cells from human cord blood generate B lymphocytes and granulocytes. Blood 89:3554, 1997

36. Young JC, Bruno E, Luens KM, Wu S, Backer M, Murray LJ: Thrombopoietin stimulates megakaryocytopoiesis, myelopoiesis, and expansion of $\mathrm{CD} 34^{+}$progenitor cells from single CD $34^{+} / \mathrm{Thy}^{-} 1^{+} / \mathrm{Lin}^{-}$ primitive progenitor cells. Blood 88:1619, 1996

37. Verfaillie CM, Miller JS: A novel single cell proliferation assay demonstrates that long-term culture-initiating cell (LTC-IC) maintenance over time results from the extensive proliferation of a small fraction of LTC-IC. Blood 86:2137, 1995

38. Moore KA, Pytowski B, Witte L, Hickling D, Lemischka IR: Hematopoietic activity of a stromal cell transmembrane protein containing epidermal growth factor-like repeat motifs. Proc Natl Acad Sci USA 94:4011, 1997

39. Smas CM, Sul HS: Pref-1, a protein containing EGF-like repeats, inhibits adipocyte differentiation. Cell 73:725, 1993

40. Muskavitch M: Delta-notch signaling and drosophila cell fate choice. Dev Biol 166:415, 1994

41. Laborda J, Sausville EA, Hoffman T, Notario V: Dlk, a putative mammalian homeotic gene differentially expressed in small cell lung carcinoma and neuroendocrine tumor cell line. J Biol Chem 268:3817, 1993

42. Moore KA, Genetti DR, Lemischka IR: Novel molecular mechanisms in the hematopoietic microenvironment. Blood 90:1786a, 1997 (abstr)

43. Moore KA, Lemischka IR: The molecular profile of a stem cell supporting microenvironment. Exp Hematol 25:28a, 1997 (abstr)

44. Verfaillie CM, Catanzarro PM: Direct contact with stroma inhibits proliferation of long-term culture initiating cells. Leukemia 10:498, 1996

45. Hurley RW, McCarthy JB, Verfaillie CM: Direct adhesion to bone marrow stroma via fibronectin receptors inhibits hematopoietic progenitor proliferation. J Clin Invest 96:5111, 1995 